\title{
Multifractal analysis of meteorological time series to assess climate impacts
}

\author{
Piotr Baranowski ${ }^{1, *}$, Jaromir Krzyszczak ${ }^{1}$, Cezary Slawinski ${ }^{1}$, Holger Hoffmann ${ }^{2}$, \\ Jerzy Kozyra ${ }^{3}$, Anna Nieróbca ${ }^{3}$, Krzysztof Siwek ${ }^{4}$, Andrzej Gluza ${ }^{4}$ \\ ${ }^{1}$ Institute of Agrophysics, Polish Academy of Sciences, ul. Doświadczalna 4, 20-290 Lublin, Poland \\ ${ }^{2}$ Institute of Crop Science and Resource Conservation (INRES), Katzenburgweg 5, 53115 Bonn, Germany \\ ${ }^{3}$ Institute of Soil Science and Plant Cultivation, State Research Institute, Czartoryskich 8, 24-100 Pulawy, Poland \\ ${ }^{4}$ Faculty of Earth Sciences and Spatial Management, UMCS, al. Kraśnicka 2cd, 20-718 Lublin, Poland
}

\begin{abstract}
Agro-meteorological quantities are often in the form of time series, and knowledge about their temporal scaling properties is fundamental for transferring locally measured fluctuations to larger scales and vice versa. However, the scaling analysis of these quantities is complicated due to the presence of localized trends and nonstationarities. The objective of this study was to characterise scaling properties (i.e. statistical self-similarity) of the chosen agro-meteorological quantities through multifractal detrended fluctuation analysis (MFDFA). For this purpose, MFDFA was performed with 11322 measured time series (31 yr) of daily air temperature, wind velocity, relative air humidity, global radiation and precipitation from stations located in Finland, Germany, Poland and Spain. The empirical singularity spectra indicated their multifractal structure. The richness of the studied multifractals was evaluated by the width of their spectrum, indicating considerable differences in dynamics and development. In log-log plots of the cumulative distributions of all meteorological parameters the linear functions prevailed for high values of the response, indicating that these distributions were consistent with power-law asymptotic behaviour. Additionally, we investigated the type of multifractality that underlies the $q$-dependence of the generalized Hurst exponent by analysing the corresponding shuffled and surrogate time series. For most of the studied meteorological parameters, the multifractality is due to different long-range correlations for small and large fluctuations. Only for precipitation does the multifractality result mainly from broad probability function. This feature may be especially valuable for assessing the effect of change in climate dynamics.
\end{abstract}

KEY WORDS: Multifractal analysis · Time series · Agro-meteorological parameters

\section{INTRODUCTION}

The interest in modelling of climate temporal and spatial variability has increased over the last few decades, mainly due to the observed symptoms of global warming. This climate evolution at the global scale has an impact on various aspects of human lives, including the necessity of adaptation, mitigation and reasonable planning of food supplies (Rötter
2014, Trnka et al. 2014). Therefore, modelling of climate change through the analysis of empirical meteorological data is of great importance. Historical and contemporary meteorological data are the main sources of input to climate change models. The standard approach to detecting climatic changes consists of measuring trends and oscillations of the relevant meteorological quantities (Balling et al. 1998). This allows researchers to confirm the projected continua- 
tion of the change in the meteorological parameters (e.g. increase in the measured air temperature both at regional and global scales; Lana et al. 2009, Martinez et al. 2010, Ludecke et al. 2011, IPCC 2013). However, this classical approach gives satisfactory results only in climatic zones with extreme climate change dynamics. Therefore, more subtle methods are being developed and applied in order to project changes in meteorological parameters in climatic zones with less extreme climate change dynamics. These include fractal analysis and chaotic evolution analysis of the atmospheric system (Kantelhardt et al. 2002, Higuchi 1988, Kalauzi et al. 2005).

Several previous reports have indicated the multifractal nature of many atmospheric and terrestrial physical and meteorological records, such as cloud distribution (Schertzer \& Lovejoy 1988), wind speed (Kavasseri \& Nagarajan 2005, Feng et al. 2009), air temperature (Koscielny-Bunde et al. 1998, Király \& Jánosi 2005, Bartos \& Jánosi 2006, Lin \& Fu 2008, Yuan et al. 2013), ocean temperature (Fraedrich \& Blender 2003), ground surface and soil temperature (Jiang et al. 2013), precipitation (Deidda 2000, García-Marín et al. 2008, de Lima \& de Lima 2009, Gemmer et al. 2011, Lovejoy et al. 2012), and ozone concentration (Jimenez-Hornero et al. 2010). Although long-range correlations in air temperature time series have been discussed by a number of authors, there is no consistency in the final conclusions (Maraun et al. 2004). Therefore, further studies are needed.

The temporal fluctuations of a time series can be expressed through the power spectral density, which describes the frequency distribution of the signal power, defined in terms of the Fourier functions. The presence of long-range correlated structures in a process is expressed by a power-law shape of the power spectrum, which is linear if plotted on a log-log scale. Such behaviour, called scaling, allows quantification of the strength of the temporal fluctuations in any process by estimating the scaling exponents (KoscielnyBunde et al. 1998). Multifractal analysis is a powerful method of characterising long-range correlations within the time series through calculation of different scaling exponents for different parts of the series (Kantelhardt et al. 2006). In recent years, the multifractal detrended fluctuation analysis (MFDFA) method has become a widely used technique for the determination of multifractal scaling properties and the detection of long-range correlations in noisy, non-stationary time series. The original version of this method (Kantelhardt et al. 2002) has been applied to the daily rainfall time series in the Pearl River basin and was compared with a universal multifractal model to show a relationship between topography and rainfall variability (Yu et al. 2014). Applying MFDFA on daily ground surface temperature records from 4 representative weather stations over China revealed considerable differences of the generalized Hurst exponents among sites (Jiang et al. 2011). These results indicate that the strength of the multifractal behaviour of ground surface temperature is non-universal and depends on the geographical location of the station. Furthermore, it was possible to establish the multifractal properties of rainfall in space and time (Valencia et al. 2010), to develop suitable models (Veneziano et al. 2006), and to use the models to predict rainfall extremes (Venugopal et al. 2006, Yonghe et al. 2013).

Recently, the combined fractal and chaos methods have been incorporated for processing of geophysical, climatic and meteorological time series (Sivakumar 2000, Kalauzi et al. 2005, Gutiérrez et al. 2006, Chaudhuri 2006). This new approach delivered information about the impact of climate variability on ecological systems. It was confirmed that understanding of meteorological dynamics is possible by analysing time series with a huge number of records collected at short time intervals (e.g. on a daily basis). Kalauzi et al. (2005) elaborated the consecutive differences method, which was used to analyse monthly meteorological records of rainfall, evaporation, relative humidity, minimum temperature, sunshine duration and evaporation/precipitation ratio from the Amazonian area in Ecuador and Verano, Italy (Kalauzi et al. 2009). Applying fast Fourier transform (FFT) to fractal dimension courses showed that fractal rhythms followed almost the same oscillation patterns as those corresponding to meteorological dynamics. It was also noticed that the fractal dimensions of all the meteorological time series ranged from 1.5 to 2 , indicating a complex chaotic structure.

Previous studies of multifractal properties of meteorological time series solely focused on analysing data from individual sites, small areas (region) or a specific meteorological quantity over a short time period (Bartos \& Jánosi 2006, García-Marín et al. 2008, de Lima \& de Lima 2009, Feng et al. 2009, Jiang et al. 2013, Rodríguez et al. 2013). Therefore, there is a need to compare multifractal properties of various long-term meteorological time series over large areas with varying climate conditions in order to generalise the differences in the dynamics of meteorological processes. Thus, the aim of the present work is to analyse spatial and time variation of multifractal properties of daily meteorological time series. 


\section{MATERIALS AND METHODS}

In this paper, we employ the MFDFA method to investigate multifractal behaviour of chosen meteorological time series in 4 regions of Europe. To determine whether climate change has any impact on multifractal spectra, we divided all meteorological time series into the subsets 1980-1995 and 19962010 to compare respective spectra.

The question arose whether the analysed time series length (11322 samples for each series) was sufficient to perform MFDFA. On the basis of the existing theoretical studies we found that the MFDFA method is less sensitive to the size of the series than other multifractal methods, e.g. wavelet transform modulus maxima (Oświęcimka et al. 2006). Detailed analysis of the influence of time series length on the precision of the MFDFA method for several mono- and multifractal models has been delivered by López \& Contreras (2013). They concluded that series as short as $2^{10}$ could be analyzed using MFDFA with a precision of some $5 \%$ at the largest values of $|q|<5$ (where $q$ is the order of the fluctuation function), and even better precision was found for $-3 \leq q \leq 3$. Cristescu et al. (2007) found that multifractal analysis gives reliable results for time series longer than 4000 samples. The same authors suggested that if the available time series is much shorter, considerably improved results are expected via a lengthening procedure consisting of repeating the available time series. Benbachir \& El Alaoui (2011) used a series of 4486 samples to analyse dynamics of the financial markets with the MFDFA method. There were also trials to apply multifractal detrended analysis to even smaller time series (e.g. Stan et al. 2013 used 2000 samples, PavónDomínguez et al. 2013 used $\sim 650$ samples). In our study we decided that our time series should not be shorter than 4000 samples; therefore, the only rational way of analysing a possible change in multispectral properties of the studied meteorological quantities in time was to use to 2 equal subsets, 1980-1995 and 1996-2010 (each containing 5000 samples). We realize that such division of the series would not take into account some observed global climate shifts, e.g. around 1980 (Huntingford et al. 2013) or 2001/2002 (Swanson \& Tsonis 2010).

\subsection{Study site and meteorological data}

The study sites were located in 4 European countries of various climatic conditions: Finland, Germany, Poland and Spain. The data used in the analysis came from 6 different stations: Jokioinen, Finland $\left(60^{\circ} 48^{\prime} \mathrm{N}, 23^{\circ} 30^{\prime} \mathrm{E}, 104 \mathrm{~m}\right.$ a.s.l. $) ;$ Dikopshof $\left(50^{\circ} 48^{\prime}\right.$ 29" N, 6 $6^{\circ} 57^{\prime} 7^{\prime \prime} \mathrm{E}, 60 \mathrm{~m}$ a.s.l.) and Nossen (51 $3^{\prime}$ $36^{\prime \prime} \mathrm{N}, 13^{\circ} 16^{\prime} 12^{\prime \prime} \mathrm{E}, 255 \mathrm{~m}$ a.s.l.), both Germany; Lleida, Spain $\left(41^{\circ} 42^{\prime} \mathrm{N}, 1^{\circ} 6^{\prime} \mathrm{E}, 337 \mathrm{~m}\right.$ a.s.l.); and Grabow (51 $24^{\prime} 59^{\prime \prime} \mathrm{N}, 21^{\circ} 58^{\prime} 09^{\prime \prime} \mathrm{E}, 152 \mathrm{~m}$ a.s.l.) and Lublin $\left(5115^{\prime} \mathrm{N}, 22^{\circ} 34^{\prime} \mathrm{E}, 170 \mathrm{~m}\right.$ a.s.l.), both Poland. The site in Jokioinen has a subarctic climate with a strong seasonality of severe winters and cold, short summers without a dry season (Köppen-Geiger climate classification: Dfc). The climate in Lleida is semiarid with Mediterranean-like precipitation patterns (annual average of $369 \mathrm{~mm}$ ), with foggy and mild winters and hot and dry summers (Köppen-Geiger climate classification: BSk). Nossen and Dikopshof represent maritime temperate climates (Köppen-Geiger climate classification: $\mathrm{Cfb}$ ); there is significant precipitation throughout the year in both German sites. The Grabow and Lublin sites have warm summer continental climates (Köppen-Geiger climate classification: Dfb); however, the site in Lublin is within the city area. We are aware that the limited number of sites from 4 different climate zones is not representative of Europe as a whole, and therefore we are unable to generalize the results for the whole range of possible climatic conditions on the continent. To indicate the differences in multifractal properties of the meteorological quantities for such a limited number of sites, our assumption is that the assumed methodology would be suitable to reveal the differences in the dynamics of meteorological processes for varied climate zones. A positive result would be a basis for a more detailed study (more sites and the whole range of climate conditions).

The weather time series of all 6 sites were measured daily from 1 January 1980 to 31 December 2010, using comparable standard equipment for all stations. Six variables were considered in the present study: air temperature $\left({ }^{\circ} \mathrm{C}\right)$, relative air humidity $(\%)$, precipitation $(\mathrm{mm})$, wind speed $\left(\mathrm{m} \mathrm{s}^{-1}\right)$ and global radiation $\left(\mathrm{W} \mathrm{m}^{-2}\right)$ (not available for the Lublin site). For Jokioinen, wind speed was measured at $10 \mathrm{~m}$ height. For comparison with measurements from other stations, it was converted to a height of $2 \mathrm{~m}$ assuming the logarithmic wind profile of Allen et al. (1998; their Eq. 47). For Lleida, the wind speed time series had gaps of 82 d in autumn 1986, and global radiation data had gaps of $48 \mathrm{~d}$ (11 d in September 1988 and $37 \mathrm{~d}$ in spring 1990). These gaps were filled by taking the absolute values of the associated grid cell in the ERAinterim dataset (Dee et al. 2011).

The descriptive statistics of the meteorological time series are presented in Table 1. The highest mean and 
Table 1. Descriptive statistics of the whole daily 31 yr meteorological time series from 6 stations in Germany (DE), Finland (FI), Poland (PL) and Spain (ES). Mean, min., max., standard deviation (SD) and median have units corresponding to the units of the meteorological variable; skewness and kurtosis are non-dimensional

\begin{tabular}{|c|c|c|c|c|c|c|c|}
\hline $\begin{array}{l}\text { Variable } \\
\text { Site }\end{array}$ & Mean & Min. & Max. & SD & Median & Skewness & Kurtosis \\
\hline \multicolumn{8}{|c|}{ Precipitation (mm d $\left.{ }^{-1}\right)$} \\
\hline Dikopshof, DE & 1.7 & 0.0 & 75.4 & 3.8 & 0.0 & 4.5 & 38.1 \\
\hline Nossen, DE & 2.0 & 0.0 & 73.5 & 4.6 & 0.0 & 4.9 & 41.5 \\
\hline Jokioinen, FI & 1.7 & 0.0 & 79.1 & 3.9 & 0.1 & 5.0 & 49.3 \\
\hline Lleida, ES & 0.9 & 0.0 & 83.6 & 3.8 & 0.0 & 7.2 & 75.7 \\
\hline Lublin, PL & 1.5 & 0.0 & 61.6 & 4.0 & 0.0 & 5.7 & 49.6 \\
\hline Grabow, PL & 1.7 & 0.0 & 105.9 & 4.6 & 0.0 & 6.0 & 63.4 \\
\hline \multicolumn{8}{|c|}{ Global radiation $\left(\mathrm{MJ} \mathrm{m}^{-2} \mathrm{~d}^{-1}\right)$} \\
\hline Dikopshof, DE & 10.6 & 0.0 & 31.7 & 7.7 & 9.0 & 0.6 & 2.4 \\
\hline Nossen, DE & 10.3 & 0.0 & 31.1 & 7.5 & 8.6 & 0.7 & 2.4 \\
\hline Jokioinen, FI & 9.1 & 0.0 & 31.7 & 8.4 & 6.4 & 0.7 & 2.3 \\
\hline Lleida, ES & 15.7 & 2.9 & 30.8 & 8.2 & 15.3 & 0.1 & 1.7 \\
\hline Grabow, PL & 10.4 & 0.0 & 31.6 & 7.8 & 8.6 & 0.5 & 2.1 \\
\hline \multicolumn{8}{|c|}{ Wind speed $\left(\mathrm{m} \mathrm{s}^{-1}\right)$} \\
\hline Dikopshof, DE & 2.6 & 0.2 & 9.4 & 1.3 & 2.4 & 1.1 & 4.8 \\
\hline Nossen, DE & 2.3 & 0.0 & 9.6 & 1.4 & 2.0 & 1.1 & 4.4 \\
\hline Jokioinen, FI & 2.3 & 0.0 & 7.7 & 1.0 & 2.6 & 0.5 & 3.5 \\
\hline Lleida, ES & 2.6 & 0.3 & 17.8 & 1.7 & 2.2 & 2.0 & 9.2 \\
\hline Lublin, PL & 2.6 & 0.0 & 10.3 & 1.2 & 2.3 & 0.8 & 3.8 \\
\hline Grabow, PL & 3.8 & 0.0 & 21.0 & 1.8 & 3.3 & 1.4 & 7.2 \\
\hline \multicolumn{8}{|c|}{ Relative air humidity (\%) } \\
\hline Dikopshof, DE & 79.2 & 33.0 & 99.8 & 11.4 & 80.7 & -0.7 & 3.1 \\
\hline Nossen, DE & 76.4 & 34.2 & 99.7 & 11.7 & 77.6 & -0.4 & 2.6 \\
\hline Jokioinen, FI & 79.4 & 37.5 & 100.0 & 11.9 & 80.0 & -0.3 & 2.2 \\
\hline Lleida, ES & 69.5 & 31.9 & 98.6 & 10.7 & 68.8 & 0.2 & 2.7 \\
\hline Lublin, PL & 76.6 & 31.6 & 100.0 & 12.2 & 77.8 & -0.4 & 2.7 \\
\hline Grabow, PL & 79.0 & 32.0 & 100.0 & 12.1 & 81.0 & -0.6 & 2.8 \\
\hline \multicolumn{8}{|c|}{ Air temperature $\left({ }^{\circ} \mathrm{C}\right)$} \\
\hline Dikopshof, DE & 10.2 & -16.8 & 28.9 & 6.8 & 10.5 & -0.2 & 2.5 \\
\hline Nossen, DE & 9.3 & -20.6 & 30.2 & 7.9 & 9.6 & -0.2 & 2.5 \\
\hline Jokioinen, FI & 4.6 & -33.4 & 25.0 & 9.3 & 4.7 & -0.4 & 2.8 \\
\hline Lleida, ES & 15.0 & -8.3 & 33.1 & 7.6 & 14.7 & 0.0 & 2.1 \\
\hline Lublin, PL & 8.7 & -22.8 & 28.3 & 8.8 & 9.1 & -0.2 & 2.4 \\
\hline Grabow, PL & 8.1 & -26.6 & 27.6 & 8.7 & 8.6 & -0.3 & 2.5 \\
\hline
\end{tabular}

median values of air temperature and global radiation in the 31 yr period were observed at the Lleida station and the lowest at the Jokioinen station. The highest mean and median values of relative air humidity were observed at Jokioinen, and the lowest at Lleida. The skewness and kurtosis parameters of the analysed time series give information about differences in their statistical distributions. Air temperature and relative air humidity are characterized by negative skewness and small kurtosis, which inform us that these distributions are left-tailed and have a more rounded peak and thinner tails compared with wind speed distribution, which is characterised by positive skewness and larger kurtosis. In contrast, precipitation showed higher positive skewness and very large kurtosis for all stations, indicating strongly right-tailed distributions with sharp peaks and fat tails.

\subsection{Data analyses}

The MFDFA of the nonstationary time series $x_{k}$ of length $N$ consists of 5 steps (Kantelhardt et al. 2002).

(1) The noises are converted into random walks by subtracting the mean value and integrating the time series. Thus the 'profile' is created as:

$$
Y(i)=\sum_{k=1}^{i}\left[x_{k}-\langle X\rangle\right] \quad i=1, \ldots, N
$$

(2) Each 'profile' is divided into $N_{s}=\operatorname{int}(N / s)$ nonoverlapping segments of equal length $s$. Since the length $N$ of the series is often not a multiple of the considered time scale $s$, a short part at the end of the profile may remain. Therefore, the same procedure should be repeated starting from the opposite end to obtain $2 N_{s}$ segments altogether. 
(3) The linear local trend for each of $2 N_{s}$ segments is calculated by a least square fit of the series, and then the variance $F^{2}(\mathrm{~s}, v)$ is determined using:

$$
\begin{gathered}
F^{2}(s, v)=\frac{1}{s} \sum_{i=1}^{s}\left\{Y[(v-1) s+i]-y_{v}(i)\right\}^{2} \quad v=1, \ldots, N_{s} \\
F^{2}(s, v)=\frac{1}{s} \sum_{i=1}^{s}\left\{Y\left[N-\left(v-N_{s}\right) s+i\right]-y_{v}(i)\right\}^{2} \\
v=N_{s}+1, \ldots, 2 N_{s}
\end{gathered}
$$

where $y_{v}(i)$ is the fitting line in segment $v$.

(4) All segments are averaged to obtain the $q$ thorder fluctuation function $F_{q}(\mathrm{~s})$ :

$$
F_{q}(s)=\left\{\frac{1}{2 N_{s}} \sum_{v=1}^{2 N_{s}}\left[F^{2}(s, v)\right]\right\}^{q / 2}
$$

(5) The scaling behaviour of the fluctuation functions is determined by analysing log-log plots $F_{q}(s)$ versus $s$ for each value of $q$. For multifractal time series, $F_{q}(s)$ increases (for large values of $s$ ), as a power law:

$$
F_{q}(s) \sim s^{h(q)}
$$

with the generalized Hurst exponent $h(q)$ depending on $q$.

The multifractal spectrum is obtained using the relationship:

$$
\tau(q)=q h(q)-1
$$

and then the Legendre transform:

$$
\begin{aligned}
& \alpha=\frac{\mathrm{d} \tau}{\mathrm{d} q} \\
& f(\alpha)=q \alpha-\tau(q)
\end{aligned}
$$

The schematic representation of a multifractal spectrum with its most important parameters $\alpha_{\max }$, $\alpha_{\min }, \alpha_{0}, a_{\mathrm{S}}$ and $w$ is shown in Fig. 1 . The parameter $\alpha_{\min }$ indicates the most extreme and $\alpha_{\max }$ the smoothest events in the studied process. A low value of $\alpha_{0}$ indicates that the underlying process becomes correlated and loses fine structure, becoming more regular in appearance. The asymmetry parameter $a_{S}$ achieves negative or positive values for a left- or right-skewed shape, respectively. The $a_{S}$ is zero for symmetric shapes. A left-skewed spectrum means low fractal exponents of small weights, which correspond to dominance of extreme events (Telesca \& Lovallo 2011). A right-skewed spectrum denotes relatively strongly weighted high fractal exponents, which correspond to fine structures. The width of the spectrum $w$ is the difference between $\alpha_{\max }$ and $\alpha_{\min }$. The width $w$ measures the length of the range of fractal exponents in the signal, indicating the 'rich-

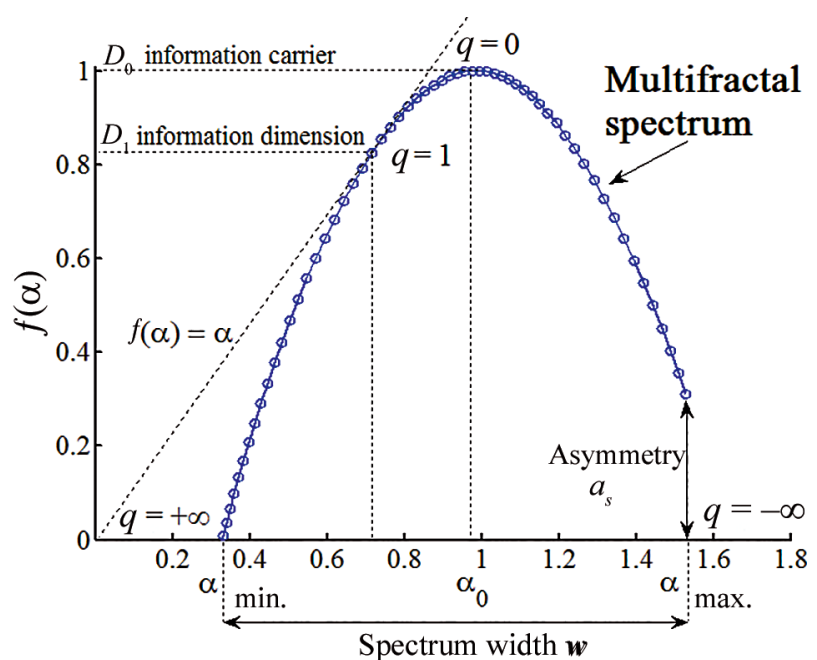

Fig. 1. Schematic representation of the main parameters of a multifractal spectrum. $D_{0}$ : information carrier; $D_{1}$ : information dimension; $\alpha$ : singularity strength; $q$ : order of the fluctuation, $a_{s}$ : asymmetry parameter

ness' of the signal structure (more developed multifractality).

Kantelhardt et al. (2002) indicated 2 possible sources of multifractality of time series: (a) multifractality due to a broad probability density function for the values of the time series, and (b) multifractality due to different long-range correlations for small and large fluctuations. To test the source of multifractality, we randomly shuffle the series to remove any temporal correlations. If the spectra narrow significantly, it means that long-term correlations play the main role in the multifractality of the data. The shuffling procedure consists of generating a random permutation of the array elements of time series. The method used to check whether the multifractality comes from broad distributions is used to analyse surrogate data. In this paper, amplitude adjusted Fourier transform (AAFT) was applied to obtain surrogates (Theiler et al. 1992). In previous studies, other surrogate methods in addition to AAFT were used for nonlinearity tests of the time series, including FFT, iterated amplitude adjusted Fourier transform (IAAFT), and statically transformed autoregressive process (STAP) (Palus et al. 2004, Palus 2008, Halley \& Kugiumtzis 2011). Palus (2008) showed that in the range of $q(-3,6)$, scaling exponent values are very similar for FFT and IAAFT surrogates. If the multifractality source is the long-range correlation, the shuffled series exhibits non-multifractal scaling, since the shuffling of time series destroys the longrange correlation. In contrast, if the multifractality in the time series is due to a broad probability density function, the spectra obtained for the AAFT surrogate data indicate no multifractality (Min et al. 2013, Mali 2014). 
To better compare the impact of a broad probability density function on multifractality, we applied the procedure (Clauset et al. 2009) based on the maximum likelihood method and the KolmogorovSmirnov statistic. This procedure is basing on comparison of the log-log cumulative distribution plots of particular time series at various sites and the power-law exponent $\beta$.

\section{RESULTS AND DISCUSSION}

In the calculations of $F_{q}(s)$ fluctuations, we used the scale $s$ ranging from 50 to 3000 events. This scale was chosen after several trials with various values. The criterion for selection of the scale was the stability of
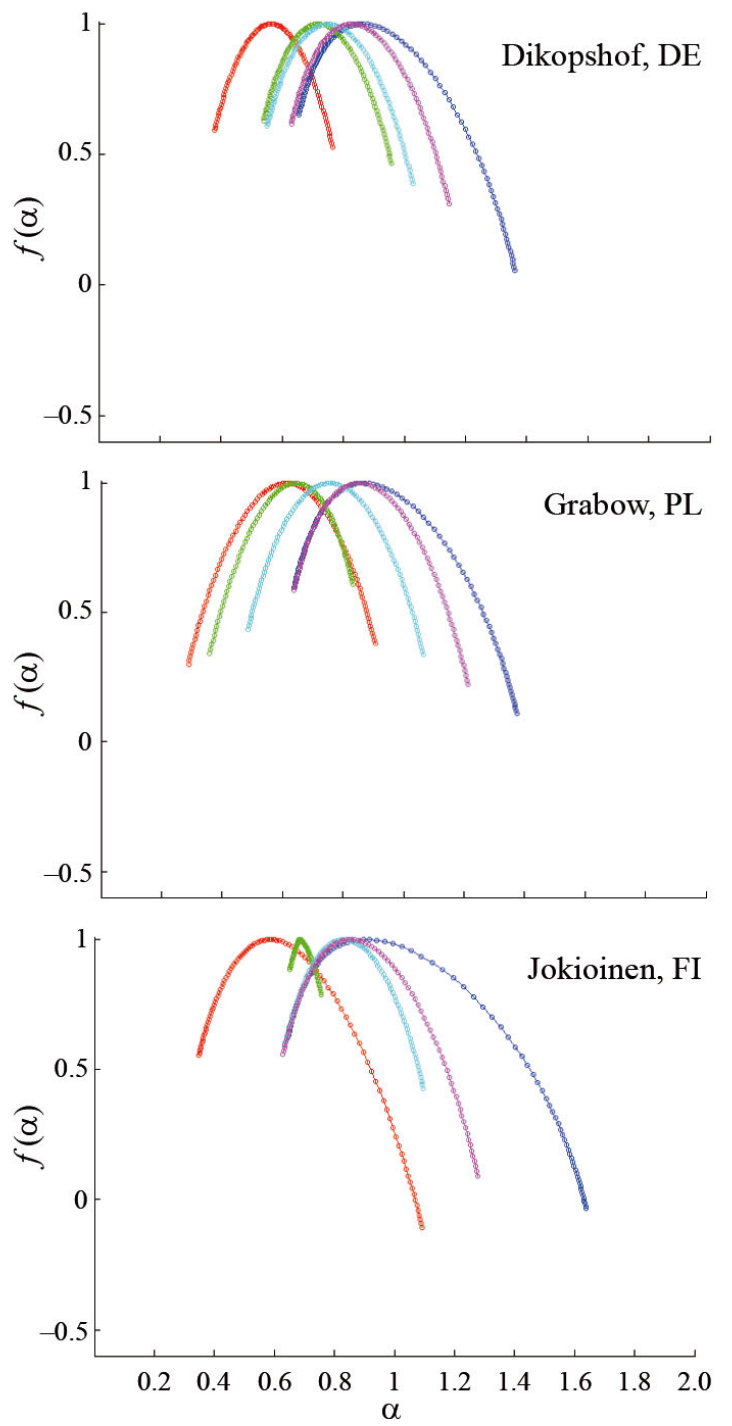

obtained spectra. The density distributions of all the studied meteorological time series had heavy tails. Therefore, the range of $q$ had to be limited to $q \in[-5$, 5] to prevent a potential distortion of the results by the so-called 'freezing' phenomenon (Kantelhardt et al. 2006).

The multifractal spectra of studied meteorological time series for particular sites are presented in Fig. 2 and the respective parameters of the spectra in Table 2 (the original data columns). These results show that multifractal analysis is a good method for assessing the differences in the dynamics of meteorological processes for the areas within various climatic zones. Firstly, the comparison of the parameters of the multifractal spectra between 2 stations in one country (in Germany or in Poland) indicates very high similar-
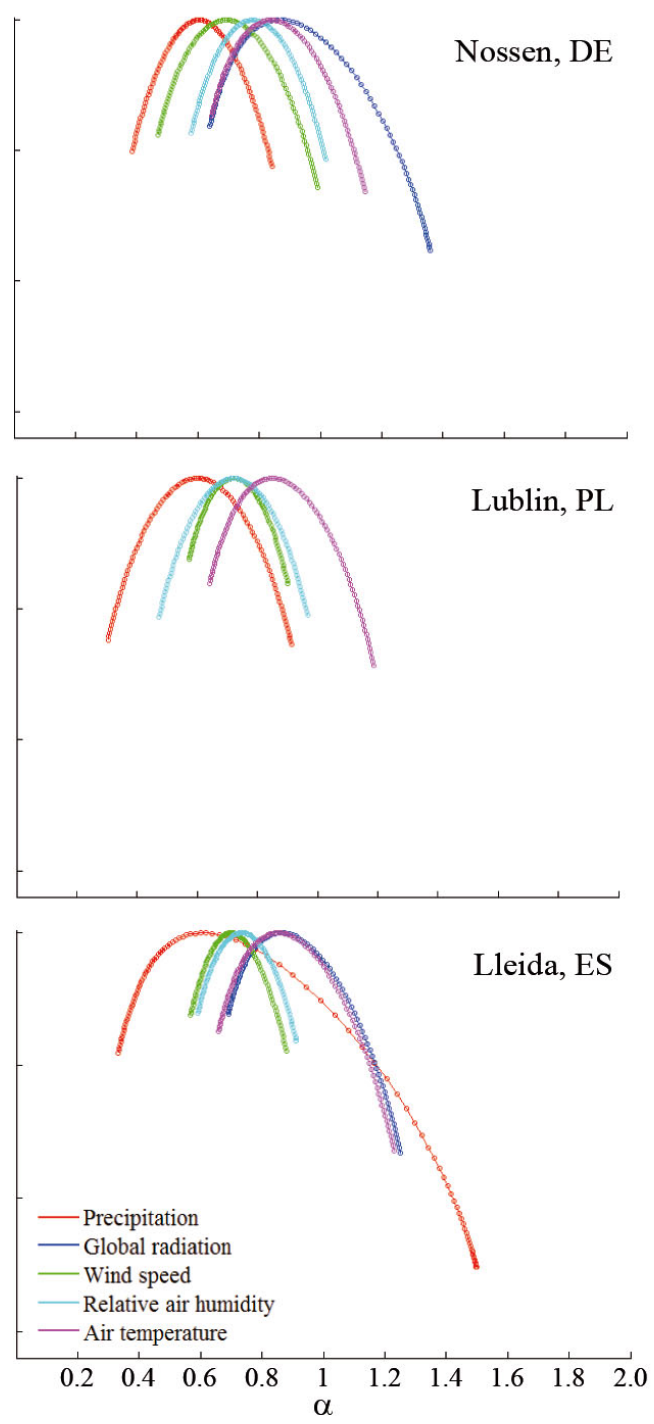

Fig. 2. Multifractal spectra of the original time series of meteorological variables from 6 stations in Germany (DE), Finland (FI), Poland (PL) and Spain (ES). $f(\alpha)$ : singularity spectrum; $\alpha$ : singularity strength 
Table 2. Dimensionless parameter values of multifractal detrenched fluctuation analysis (MFDFA) spectra of meteorological variables from 6 stations in Germany (DE), Finland (FI), Poland (PL) and Spain (ES). $\alpha_{0}$ : $\alpha$-value corresponding to the maximum of the $f(\alpha)$ function; $a_{s}$ : asymmetry parameter; $w$ : width of the multifractal spectrum

\begin{tabular}{|c|c|c|c|c|c|c|c|c|c|}
\hline \multirow{2}{*}{$\begin{array}{l}\text { Variable } \\
\text { Site }\end{array}$} & \multicolumn{3}{|c|}{ Original data } & \multicolumn{3}{|c|}{ Shuffled data } & \multicolumn{3}{|c|}{ Surrogate data } \\
\hline & $\alpha_{0}$ & $a_{s}$ & $w$ & $\alpha_{0}$ & $a_{s}$ & $w$ & $\alpha_{0}$ & $a_{s}$ & $w$ \\
\hline \multicolumn{10}{|l|}{ Precipitation } \\
\hline Dikopshof, DE & 0.57 & 0.06 & 0.39 & 0.52 & -0.09 & 0.25 & 0.75 & 0.57 & 0.64 \\
\hline Nossen, DE & 0.61 & 0.06 & 0.46 & 0.53 & 0.01 & 0.30 & 0.85 & 0.39 & 0.70 \\
\hline Jokioinen, FI & 0.59 & 0.66 & 0.74 & 0.58 & 0.00 & 0.26 & 0.79 & 0.26 & 0.71 \\
\hline Lleida, ES & 0.62 & 0.81 & 1.17 & 0.53 & 0.08 & 0.71 & 2.73 & 0.46 & 8.93 \\
\hline Lublin, PL & 0.61 & 0.02 & 0.61 & 0.60 & 0.09 & 0.21 & 0.76 & 0.65 & 1.09 \\
\hline Grabow, PL & 0.62 & -0.08 & 0.62 & 0.53 & -0.01 & 0.34 & 0.82 & 0.28 & 0.65 \\
\hline \multicolumn{10}{|l|}{ Global radiation } \\
\hline Dikopshof, DE & 0.87 & 0.59 & 0.71 & 0.53 & 0.00 & 0.12 & 0.86 & 0.60 & 0.69 \\
\hline Nossen, DE & 0.87 & 0.47 & 0.72 & 0.44 & -0.05 & 0.08 & 0.89 & 0.55 & 0.80 \\
\hline Jokioinen, FI & 0.92 & 0.66 & 0.99 & 0.54 & -0.15 & 0.05 & 0.94 & 0.60 & 1.02 \\
\hline Lleida, ES & 0.87 & 0.52 & 0.56 & 0.51 & -0.13 & 0.09 & 0.86 & 0.44 & 0.51 \\
\hline Grabow, PL & 0.88 & 0.49 & 0.74 & 0.48 & 0.02 & 0.10 & 0.86 & 0.56 & 0.74 \\
\hline \multicolumn{10}{|l|}{ Wind speed } \\
\hline Dikopshof, DE & 0.72 & 0.16 & 0.42 & 0.54 & -0.04 & 0.08 & 0.70 & -0.03 & 0.24 \\
\hline Nossen, I & 0.70 & 0.20 & 0.52 & 0.46 & -0.02 & 0.13 & 0.67 & 0.11 & 0.38 \\
\hline Jokioinen, FI & 0.68 & 0.10 & 0.11 & 0.46 & 0.00 & 0.11 & 0.74 & -0.08 & 0.05 \\
\hline Lleida, ES & 0.70 & 0.13 & 0.31 & 0.53 & -0.02 & 0.02 & 0.74 & -0.29 & 0.45 \\
\hline Lublin, PL & 0.72 & 0.09 & 0.33 & 0.48 & -0.03 & 0.07 & 0.73 & -0.19 & 0.32 \\
\hline Grabow, PL & 0.65 & -0.27 & 0.47 & 0.58 & 0.02 & 0.01 & 0.63 & 0.03 & 0.26 \\
\hline \multicolumn{10}{|c|}{ Relative air humidity } \\
\hline Dikopshof, DE & 0.75 & 0.22 & 0.48 & 0.52 & -0.12 & 0.1 & 0.75 & 0.20 & 0.41 \\
\hline Nossen, DE & 0.78 & 0.10 & 0.44 & 0.53 & -0.06 & 0.11 & 0.79 & 0.07 & 0.38 \\
\hline Jokioinen, FI & 0.84 & 0.17 & 0.46 & 0.56 & 0.02 & 0.09 & 0.84 & 0.24 & 0.39 \\
\hline Lleida, ES & 0.74 & 0.11 & 0.32 & 0.49 & -0.09 & 0.11 & 0.74 & 0.05 & 0.29 \\
\hline Lublin, PL & 0.72 & -0.01 & 0.49 & 0.49 & -0.10 & 0.15 & 0.72 & 0.09 & 0.34 \\
\hline Grabow, PL & 0.76 & 0.10 & 0.58 & 0.54 & -0.06 & 0.15 & 0.77 & 0.10 & 0.48 \\
\hline \multicolumn{10}{|l|}{ Air temperature } \\
\hline Dikopshof, DE & 0.83 & 0.31 & 0.52 & 0.53 & -0.07 & 0.06 & 0.84 & 0.38 & 0.57 \\
\hline Nossen, DE & 0.84 & 0.29 & 0.50 & 0.53 & -0.10 & 0.08 & 0.83 & 0.33 & 0.53 \\
\hline Jokioinen, FI & 0.86 & 0.47 & 0.65 & 0.50 & -0.05 & 0.07 & 0.86 & 0.35 & 0.64 \\
\hline Lleida, ES & 0.86 & 0.45 & 0.57 & 0.52 & -0.24 & 0.05 & 0.86 & 0.37 & 0.59 \\
\hline Lublin, PL & 0.85 & 0.31 & 0.55 & 0.48 & -0.07 & 0.15 & 0.86 & 0.27 & 0.55 \\
\hline Grabow, PL & 0.86 & 0.36 & 0.58 & 0.45 & -0.04 & 0.08 & 0.85 & 0.31 & 0.56 \\
\hline
\end{tabular}

ity of nearly all parameters of the studied quantities. The highest difference in the width of spectra is observed for wind speed (0.14) and relative air humidity $(0.09)$ between Polish sites. The parameter $\alpha_{0}$ is almost indistinguishable between all stations, except for wind speed in Lublin and Grabow, for which the difference is also small and equals 0.07. Only the asymmetry parameter $a_{s}$ for wind speed differs greatly between the 2 Polish sites. This can be explained by the fact that Lublin is situated within the city area, whereas Grabow is a typical field. The latter is located near the river Vistula, which influences the air circulation in this area. This influence is especially reflected in the difference in sign in the asymmetry parameter of wind speed at the Grabow site, indicating dominant extreme events. The obtained result is in agreement with that of Gołaszewski (2004), who showed that the vicinity of the Vistula river influences the dynamics of the air circulation, which is connected with the specific landform of the area including heterogeneous flat morainic plateaus and parts of the undulate plateau, as well as with specific air humidity and temperature conditions. The course of the Vistula valley from south to north is conducive to the meridional exchange of air masses, and the moraine plateaus extending on both sides of the valley influence not only the direction but also the speed of winds from the western and eastern sectors. Consistently, a finer structure is observed for Lublin, which is expected for urban areas. Secondly, the $a_{\mathrm{s}}$ and $w$ parameters for the majority of meteorological time series differ vastly for the Jokioinen and Lleida stations compared with the other stations. Similar differences are observed for the air temperature, for which the width parameter is the highest for Jokioinen (0.65), which means that the signal structure is richest for this site; in addition, $a_{s}$ is highest for Jokioinen and Lleida, with the corresponding spectra being rightskewed, which means that the signal has the finest structure with high fractal exponents for these sites. It is the same with precipitation, for which the spectrum width is the highest for Lleida (1.17) followed by Jokioinen (0.74), both higher than that of the other stations ( 0.4 for German stations and $\sim 0.6$ for Polish stations). Furthermore, the $a_{S}$ for precipitation is the highest for Lleida and Jokioinen (0.81 and 0.66 , respectively). The wind speed multifractal spectrum for Jokioinen is the narrowest (the lowest $w=0.11$ ) and differs from other spectra for other sites. This result can be attributed to the conversion of wind speed data measured at $10 \mathrm{~m}$ height to $2 \mathrm{~m}$ using the Allen formulae (Allen et al. 1998). The solar radiation dynamics for Jokioinen differs from that of other sites (the highest $\alpha_{0}, a_{s}$ and $w$ ), and in Lleida the signal structure is less complex compared with that of the other sites (the lowest width). Even if 
$\alpha_{0}$ has almost the same values for all stations for a particular meteorological parameter, its value differs between meteorological parameters. The highest $\alpha_{0}$ can be observed for solar radiation and air temperature $(\geq 0.83)$ and the lowest for precipitation (between 0.57 and 0.62 ), which means that solar radiation and air temperature are characterised by finer structure than precipitation.

To determine whether the source of multifractality was the long-range correlations or the broad probability density function, the shuffled and surrogated multifractal spectra were analysed (Figs. $3 \& 4$, Table 2). It is evident from the spectra of the shuffled data for all meteorological parameters (except precipitation) that they exhibit the features of monofractality (width $w$ close to 0.0 and $\alpha_{0}$ close to 0.5 ). This result suggests
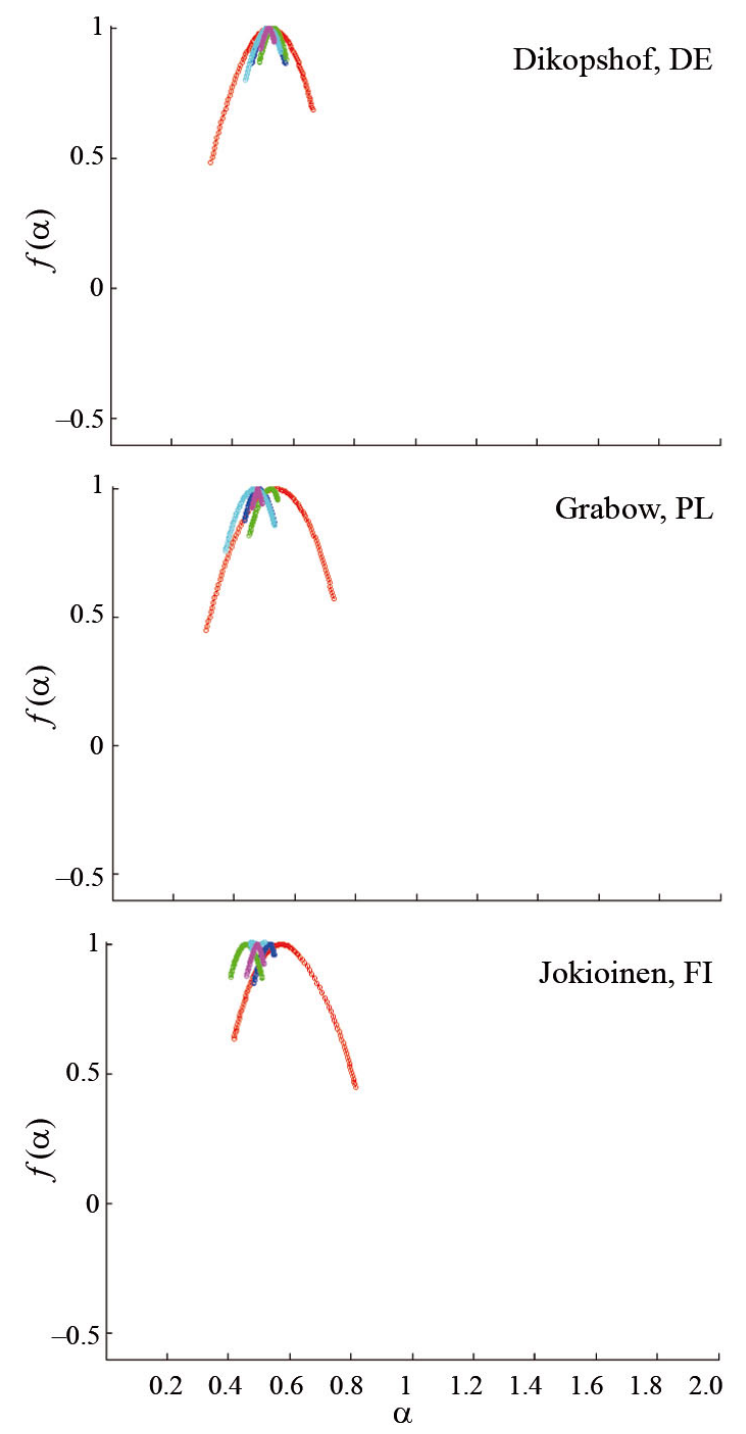

that long-range correlations are the main source of multifractality for air temperature, relative air humidity, wind speed and solar radiation for all stations, and that a broad probability density function may be dominant for precipitation multifractality. Almost the same conclusion results from the analysis of surrogate time series. The procedure of obtaining surrogate data preserves long-range correlations and randomizes phase correlations. Therefore, if surrogate multifractal spectra are similar to the original spectra, the multifractality of the time series does not depend strongly on the broadness of the probability density functions. Such a result can be observed in Fig. 4 and Table 2, which show that surrogate spectra for air temperature, relative air humidity and solar radiation are very similar to the spectra for original data. The
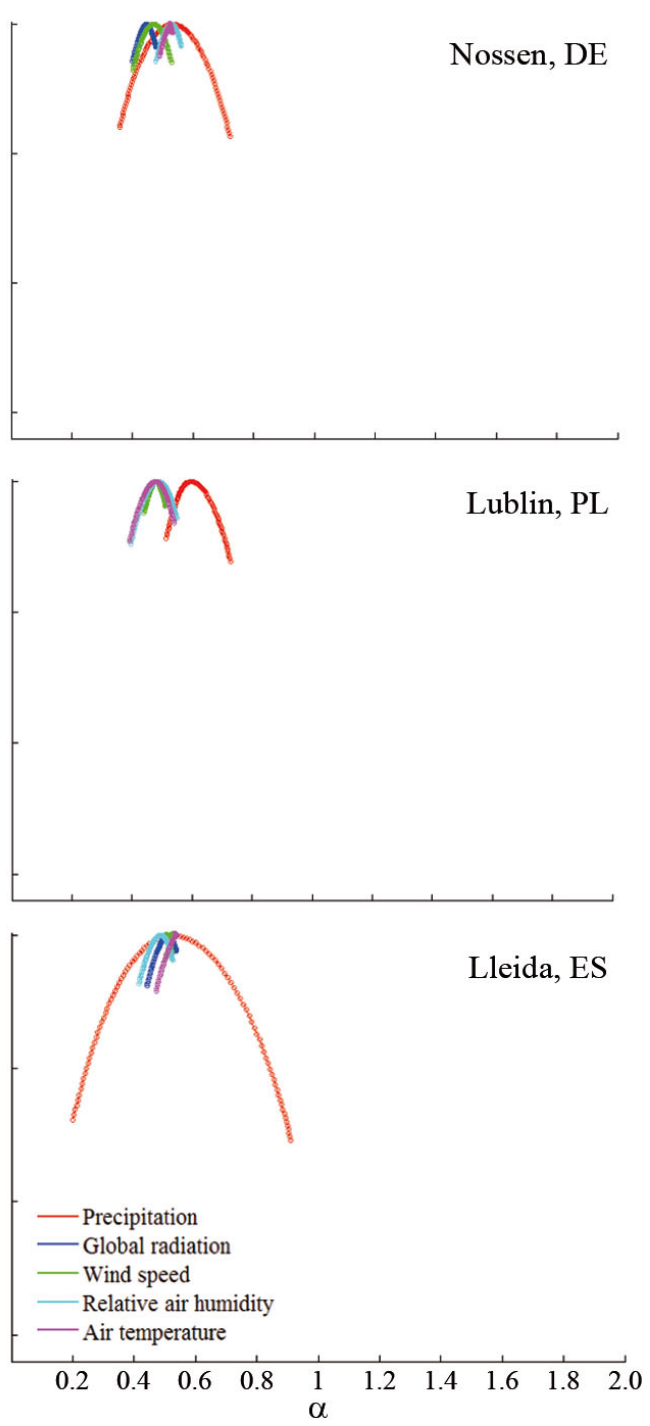

Fig. 3. Multifractal spectra of the shuffled time series of meteorological variables from 6 stations in Germany (DE), Finland (FI), Poland (PL) and Spain (ES). $f(\alpha)$ : singularity spectrum; $\alpha$ : singularity strength 
precipitation spectra for surrogate data evidently change in relation to the original data, which indicates that the broadness of the probability density function can be a main source of multifractality. Additionally, we can conclude from the surrogate data analysis that the multifractality of the wind speed spectra may depend on the broadness of the probability density function, as the spectra of surrogate data differ slightly from the spectra of the original data. The use of AAFT and FFT surrogate data to distinguish the source of multifractality in the studied time series is compared in Figs. S1 \& S2 in the Supplement at www.int-res.com/articles/suppl/c065p039_ supp.pdf. The results of this comparison confirm the multifractality of the time series analysed in Figs. $2 \& 4$.
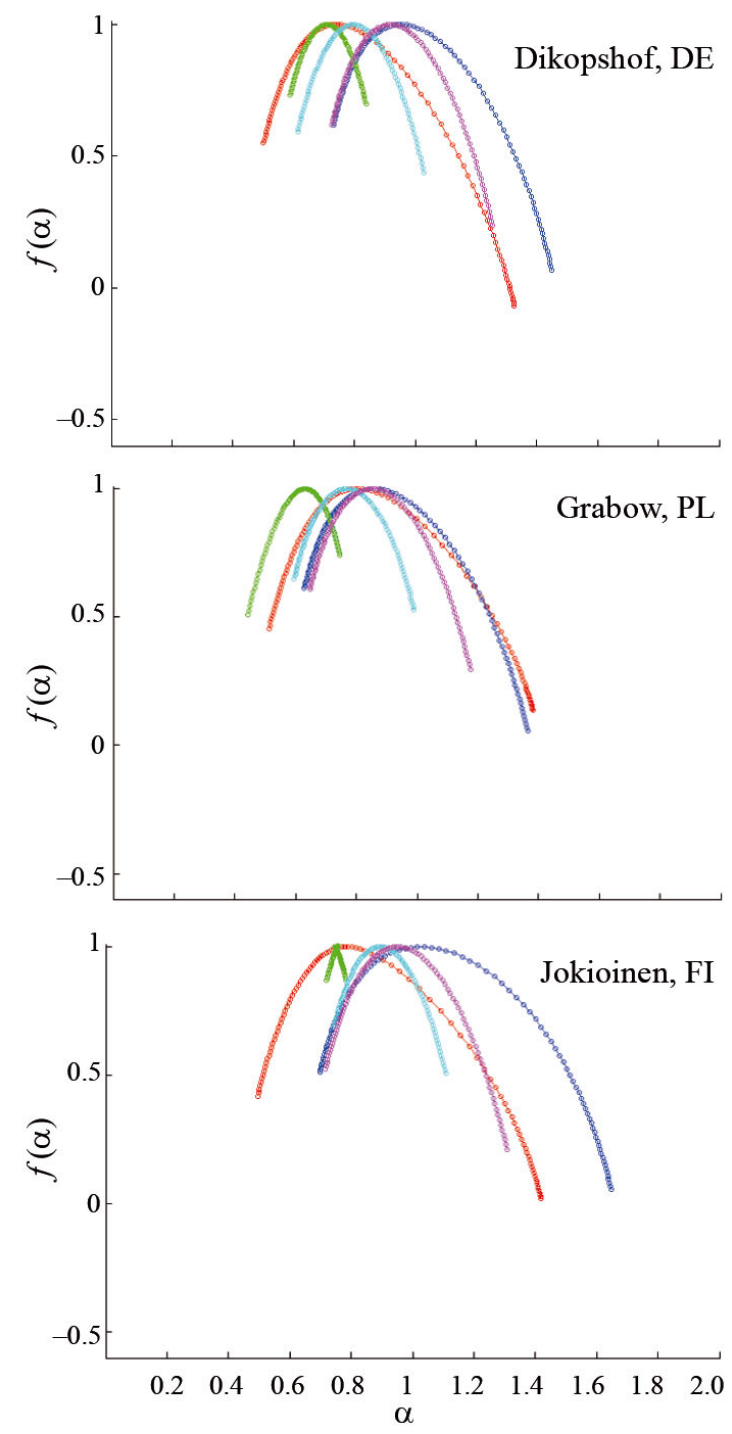

To determine more precisely the source of multifractality of the spectra, the cumulative distributions of the meteorological time series of the original data were analysed (Fig. 5). Together with the cumulative distributions shown in Fig. 5, the method elaborated by Clauset et al. (2009) was used to identify the range over which the power law holds in distributions, which refers to large fluctuations that occur in the distribution's tail. To compare the broadness of the tails for these distributions, the power-law $\beta$ exponents were also calculated for the selected tail regions for which power-law distribution was preserved. This analysis showed that precipitation distributions possess the broadest tails (the smallest $\beta$ parameter values) for all sites (Fig. 5). The other meteorological parameters have distributions with
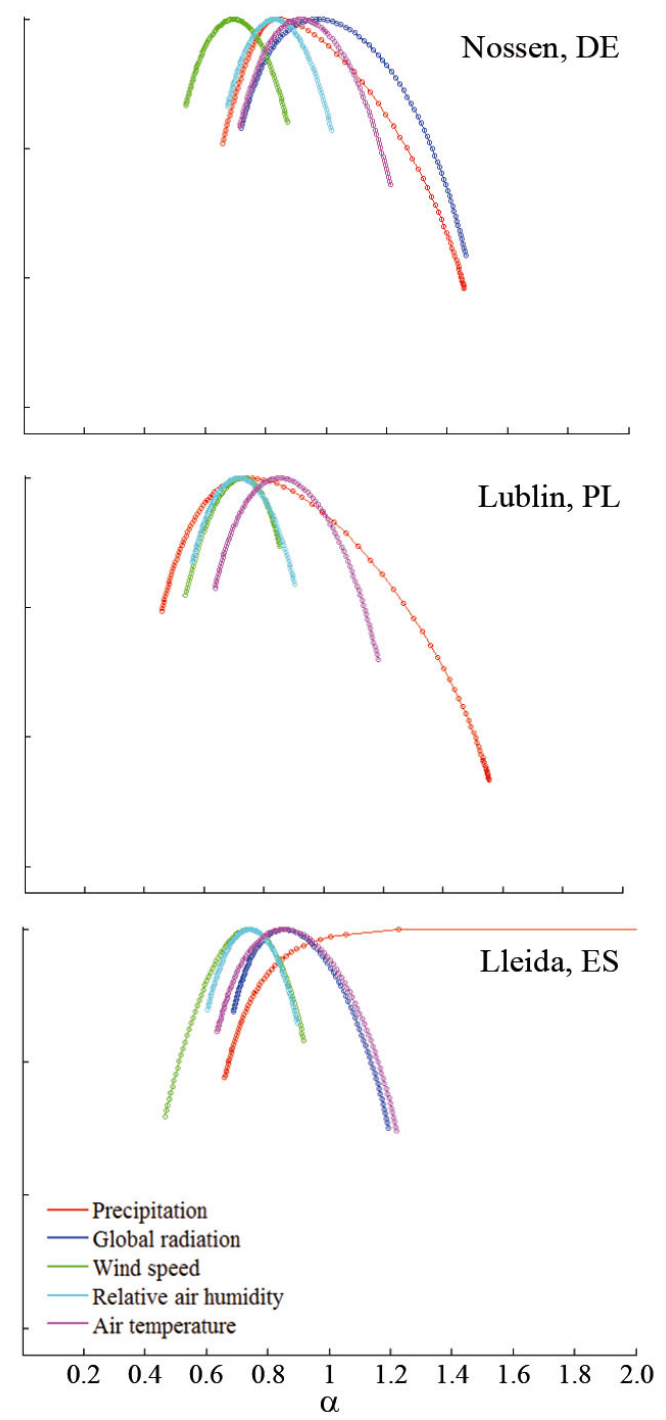

Fig. 4. Multifractal spectra of the surrogate time series of meteorological variables from 6 stations in Germany (DE), Finland (FI), Poland (PL) and Spain (ES). $f(\alpha)$ : singularity spectrum; $\alpha$ : singularity strength 

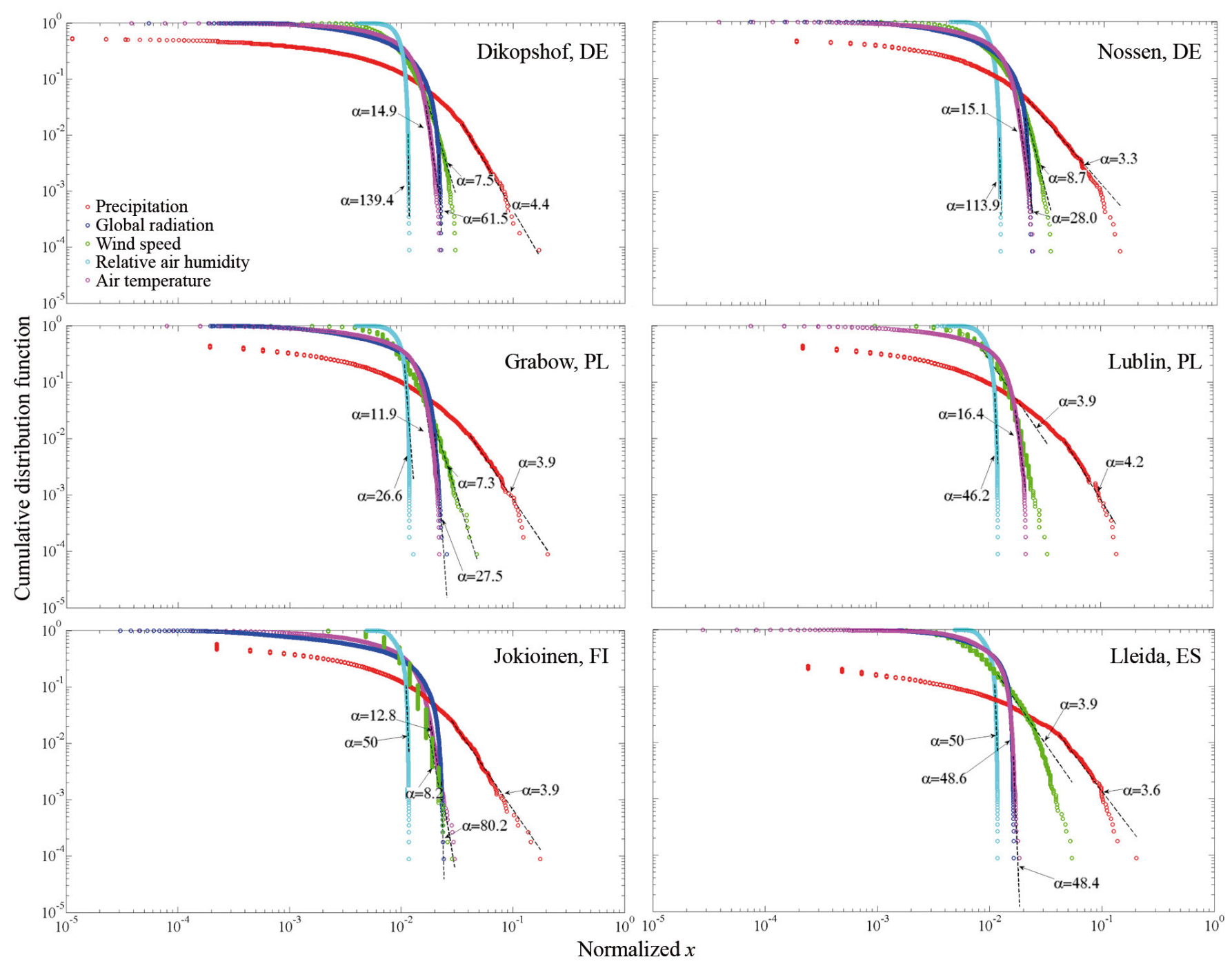

Fig. 5. Cumulative distributions of the meteorological time series of original data of meteorological variables from 6 stations in Germany (DE), Finland (FI), Poland (PL) and Spain (ES). $\alpha$ : singularity strength; $x$ : values of time series

significantly narrower tails (higher $\beta$ parameter values), with the exception of wind speed distribution, especially for Lublin and Lleida. The fractal powerlaw exponents are related to the asymmetry parameter $a_{s}$ presented in Table 2. This reflects the occurrence of extreme events in the dynamics of the spectra; therefore, parameters with the smallest $\beta$ should also have the lowest $a_{s}$. In general, this behaviour is maintained for the majority of analysed parameters (with the exception of precipitation for Jokioinen and Lleida). The above result indicates that the effect of the broad probability density function on multifractality is the highest for the precipitation and, to a lesser extent, wind speed time series. This is confirmed by the analysis of the absolute differences of Hurst exponents for original and shuffled data $I h(q)-$ $h_{\text {shuf }}(q)|=| h_{\text {cor }}(q) \mid$ and original and surrogate data $\left|h(q)-h_{\text {sur }}(q)\right|=\left|h_{\mathrm{PDF}}(q)\right|$ as a function of $q$ for the studied meteorological time series (Fig. 6). For all sites and all meteorological time series, for almost all values of $q$, with the exception of precipitation, $\left|h_{\text {cor }}(q)\right|$ is larger than $\mid h_{\mathrm{PDF}}(q)$ l. This means that only for precipitation is the effect of the broad probability density function on multifractality more important than that of long-range correlations. However, non-zero values of $\left|h_{\text {cor }}(q)\right|$ and $\left|h_{\mathrm{PDF}}(q)\right|$ indicate that both influence the mutifractality. In specific cases (Lublin for high positive values of $q$ and Jokioinen for high negative values of $q$ ), the long-range correlations have a slightly greater effect on multifractality of the precipitation time series than the broad probability density function, as $\left|h_{\text {cor }}(q)\right|>\left|h_{\text {PDF }}(q)\right|$. For the rest of the ana- 

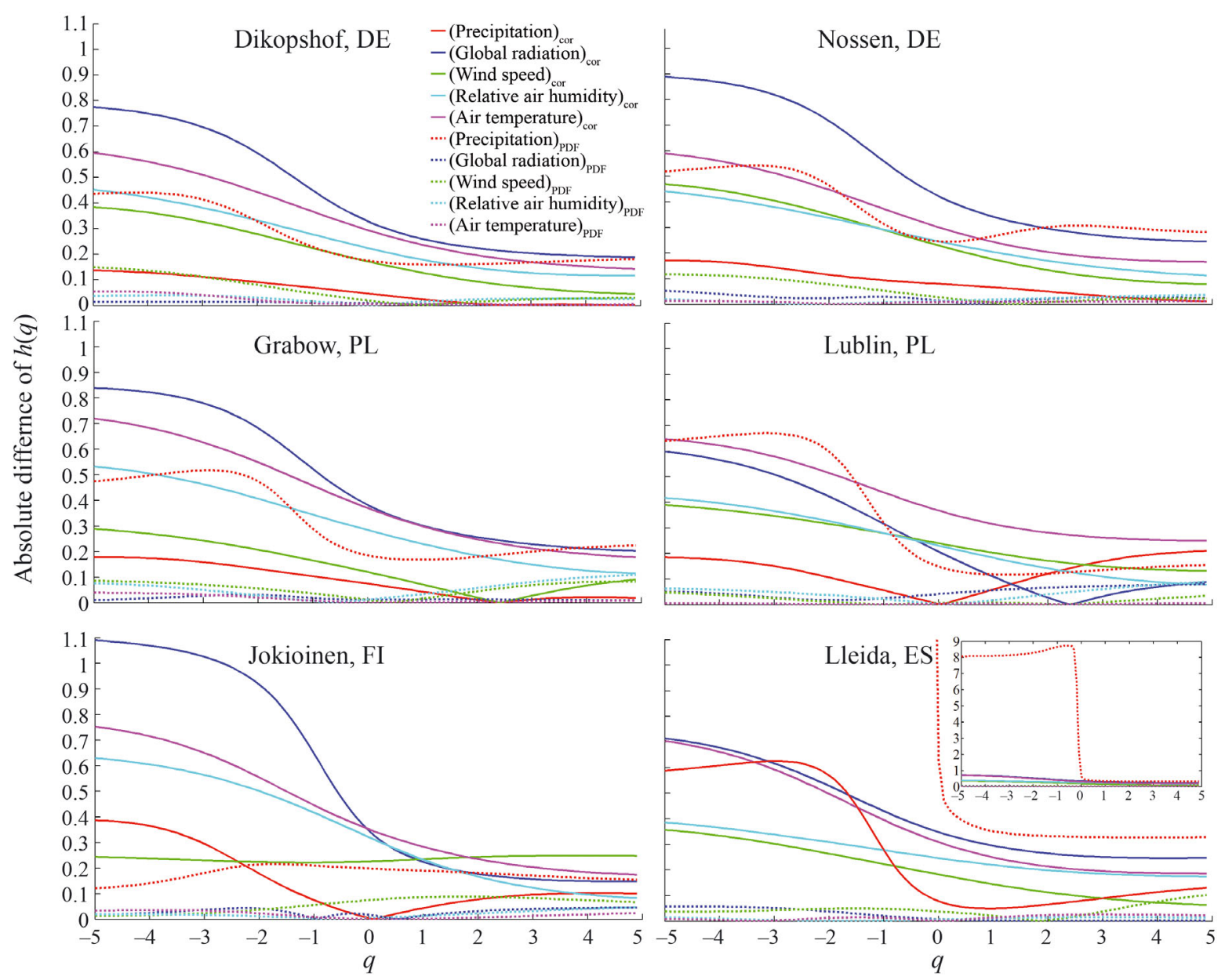

Fig. 6. Absolute difference of Hurst exponents for original and shuffled data $\left|h(q)-h_{\text {shuf }}(q)\right|=\left|h_{\text {cor }}(q)\right|$ and original and surrogate data $\left|h(q)-h_{\text {sur }}(q)\right|=\left|h_{\mathrm{PDF}}(q)\right|$ as a function of $q$ (where $q$ is the order of the fluctuation function) for the studied meteorological time series from 6 stations in Germany (DE), Finland (FI), Poland (PL) and Spain (ES)

lysed meteorological time series, $\left|h_{\mathrm{PDF}}(q)\right|$ has small, almost zero values and $\left|h_{\text {cor }}(q)\right|$ is high, which indicates that multifractality results mostly from longrange correlations. We also observed that for the wind speed time series for Grabow and Lleida, in limited ranges of $q,\left|h_{\mathrm{PDF}}(q)\right|$ is slightly higher than $\left|h_{\text {cor }}(q)\right|$. This means that multifractality in these ranges of $q$ is influenced to a greater extent by the broad probability density function than by the longrange correlations.

To determine whether changes in the dynamics of meteorological time series can be assessed with the MFDFA method, the $31 \mathrm{yr}$ of data were divided into 2 separate datasets, the first from 1980 to 1995 and the second from 1996 to 2010 . The comparison of $\alpha_{0}$, $a_{s}$ and $w$ of multifractal spectra of all of the studied meteorological parameters from these 2 periods is presented in Fig. 7. No explicit direction of changes for individual parameters for any of the studied sta- tions was observed, although there were considerable differences between the analysed periods, especially for $a_{s}$ and $w$, among various stations. The lowest differences, independent of the analysed parameter or station, were observed for $\alpha_{0}$, indicating that the structure of all the studied signals was preserved in the 2 studied periods. The changes in $a_{s}$ are more evident, especially for precipitation in Grabow (change from high positive to low negative value, indicating that extreme events dominate in the dynamics during the second period, whereas in first fine structure prevails) and Jokioinen (change from higher positive to lower positive value, indicating that fine structure of the signal was preserved, but in the second period more extreme events happened) and air temperature in Grabow (change from positive to higher positive). The width of the

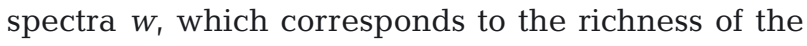
signal, also changed during the studied periods, 


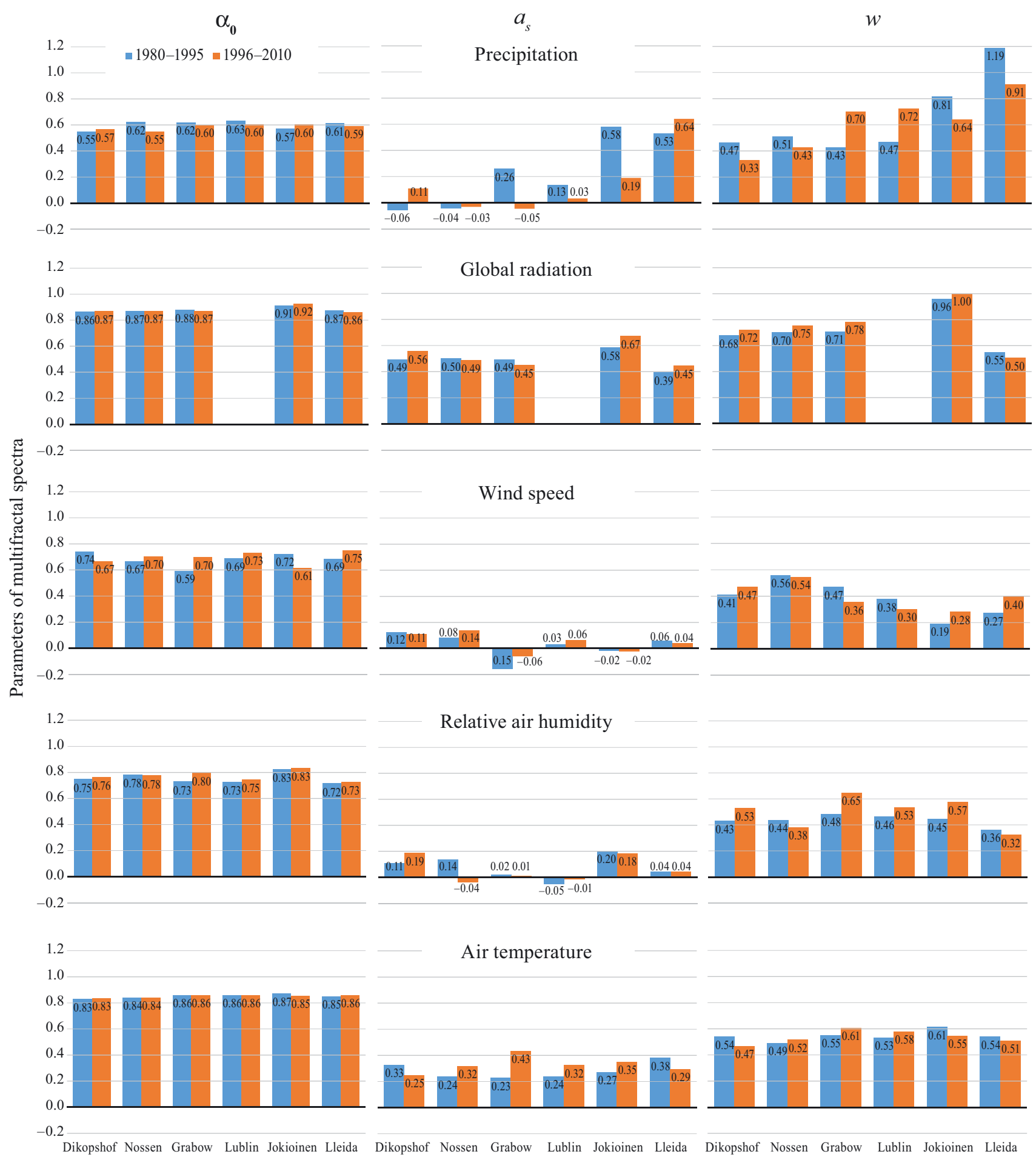

Fig. 7. Comparison of computed parameters (dimensionless) of multifractal spectra for the data divided into 2 separate periods: 1980 to 1995 and 1996 to 2010. $\alpha_{0}$ : $\alpha$-value corresponding to the maximum of the $f(\alpha)$ function; $a_{s}$ : asymmetry parameter; $w$ : width of the multifractal spectrum

especially for precipitation for all stations and air humidity for Grabow. Therefore, multifractal properties could be regarded as good indicators of changes in the dynamics of meteorological signals.
In spite of the observed differences in multifractal spectra properties in the 2 studied periods, it is not possible to identify similarities in the direction of changes for all stations. 


\section{CONCLUSIONS}

The dynamics of meteorological time series for 6 stations located in various European climate zones were analysed via MFDFA. The results indicated that the studied meteorological quantities possess specific time and space dynamics, which can be attributed to climatic conditions.

The main source of multifractality for precipitation is the broad probability density function. Additionally, the shape of the precipitation distribution varied from that of other studied quantities, with higher positive skewness and very large kurtosis values for all stations. The results indicate that the multifractal spectrum of precipitation deviates significantly from spectra of other climate variables. In contrast to precipitation, for global radiation, air humidity, wind speed and air temperature, the long-range correlations prevail, with the broadness of the probability density function influencing wind speed multifractality to a greater degree.

Our findings indicate that among the meteorological variables studied here, precipitation is the most vulnerable to changes in climate dynamics due to multifractality resulting mainly from the broad probability density function and not the long-range correlations. This is reflected in the larger changes in asymmetry and width parameters of multifractal spectra for divided datasets. To improve our knowledge on the dynamics of meteorological processes at the continent scale, these findings should be confirmed by research employing further long-term records of stations located in an even wider variety of climate zones. We hope that further studies will be able to deal with meteorological data from so many sites, that the numerical stability and mapping of multifractal properties will be possible, and thus the conclusions will be more general.

Acknowledgements. This paper has been partly financed from funds from the Polish National Centre for Research and Development from the project FACCE JPI Knowledge Hub 'Modelling European Agriculture with Climate Change for Food Safety' (MACSUR) contract FACCE JPI/06/2012. We acknowledge the data providers in the European Climate Assessment \& Dataset project (ECA\&D) - for Lleida, the Agencia Estatal de Meteorología (AEMET) (Klein Tank et al. 2002). Data and metadata are available at www.ecad.eu. We acknowledge the Finnish Meteorological Institute (FMI) for delivering the data for Jokioinen (Venäläinen et al. 2005), and Agrometeorological Network Saxony (Saxony Ministry for Environment and Agriculture) for delivering the Nossen data (gaps were interpolated from station data from the German Meteorological Service). H.H. acknowledges financial support from the German Federal Ministries of Education and Research as well as Food and Agriculture (grant no. 2812ERA115).

\section{LITERATURE CITED}

Allen RG, Pereira LS, Raes D, Smith M (1998) Crop evapotranspiration-guidelines for computing crop water requirements. FAO Irrigation and Drainage Paper 56, FAO, Rome

> Balling RC, Vose RS, Weber GR (1998) Analysis of long-term European temperature records: 1751-1995. Clim Res 10: 193-200

Bartos I, Jánosi IM (2006) Nonlinear correlations of daily temperature records over land. Nonlinear Process Geophys 13:571-576

Benbachir S, El Alaoui M (2011) A multifractal detrended fluctuation analysis of the Moroccan stock exchange. Int Res J Finance Econ 78:6-17

> Chaudhuri S (2006) Predictability of chaos inherent in the occurrence of severe thunderstorms. Adv Complex Syst 9:77-85

Clauset A, Shalizi CR, Newman MEJ (2009) Power-law distributions in empirical data. SIAM Rev 51:661-703

Cristescu CP, Stan C, Scarlat EI (2007) Multifractal analysis of the dynamics of the Romanian exchange rate ROLUSD during the transition period. UPB Sci Bull Ser A 69: $37-44$

de Lima MIP, de Lima JLMP (2009) Investigating the multifractality of point precipitation in the Madeira archipelago. Nonlinear Process Geophys 16:299-311

Dee D, Uppala S, Simmons A, Berrisford P and others (2011) The ERA-Interim reanalysis: configuration and performance of the data assimilation system. QJR Meteorol Soc 137:553-597

> Deidda R (2000) Rainfall downscaling in a space-time multifractal framework. Water Resour Res 36:1779-1794

> Feng T, Fu Z, Deng X, Mao J (2009) A brief description to different multi-fractal behaviors of daily wind speed records over China. Phys Lett A 373:4134-4141

Fraedrich K, Blender R (2003) Scaling of atmosphere and ocean temperature correlations in observations and climate models. Phys Rev Lett 90:108501

García-Marín AP, Jiménez-Hornero FJ, Ayuso JL (2008) Applying multifractality and the self-organized criticality theory to describe the temporal rainfall regimes in Andalusia (southern Spain). Hydrol Process 22:295-308

Gemmer M, Fischer T, Su B, Liu LL (2011) Trends of precipitation extremes in the Zhujiang River Basin, South China. J Clim 24:750-761

Gołaszewski D (2004) Assessment of influence of river valleys on meteorological parameters. Sci Rev Eng Environ Sci 29:55-64

Gutiérrez JM, Galván A, Cofiño AS (2006) Chaos game characterization of temporal precipitation variability: application to regionalization. Fractals 14:87-99

Halley JM, Kugiumtzis D (2011) Nonparametric testing of variability and trend in some climatic records. Clim Change 109:549-568

> Higuchi T (1988) Approach to an irregular time series on the basis of the fractal theory. Physica D 31:277-283

Huntingford C, Jones PD, Livina VN, Lenton TM, Cox PM (2013) No increase in global temperature variability despite changing regional patterns. Nature 500:327-330

IPCC (2013) Climate change 2013: the physical science basis. In: Stocker TF, Qin D, Plattner GK, Tignor M and others (eds) Contribution of Working Group I to the Fifth Assessment Report of the Intergovernmental Panel on Climate Change. Cambridge University Press, Cambridge, p 3-29

Jiang L, Zhao J, Li N, Li F, Guo Z (2013) Different multifractal scaling of the $0 \mathrm{~cm}$ average ground surface tempera- 
ture of four representative weather stations over China. Adv Meteorol 2013:341934, doi:10.1155/2013/341934

Kalauzi A, Spasić S, Ćulić M, Grbić G, Martać Lj (2005) Consecutive differences as a method of signal fractal analysis. Fractals 13:283-292

Jimenez-Hornero FJ, Jimenez-Hornero JE, de Rave EG, Pavon-Dominguez P (2010) Exploring the relationship between nitrogen dioxide and ground-level ozone by applying the joint multifractal analysis. Environ Monit Assess 167:675-684

Kalauzi A, Cukic M, Millán H, Bonafoni S, Biondi R (2009) Comparison of fractal dimension oscillations and trends of rainfall data from Pastaza Province, Ecuador and Veneto, Italy. Atmos Res 93:673-679

Kantelhardt JW, Zschiegner SA, Koscielny-Bunde E, Havlin S, Bunde A, Stanley HE (2002) Multifractal detrended fluctuation analysis of nonstationary time series. Physica A 316:87-114

Kantelhardt JW, Koscielny-Bunde E, Rybski D, Braun P, Bunde A, Havlin S (2006) Long-term persistence and multifractality of precipitation and river runoff records. J Geophys Res 111:D01106

> Kavasseri RG, Nagarajan R (2005) A multifractal description of wind speed records. Chaos Solitons Fractals 24:165-173

Király A, Jánosi IM (2005) Detrended fluctuation analysis of daily temperature records: geographic dependence over Australia. Meteorol Atmos Phys 88:119-128

Klein Tank AMG, Wijngaard JB, Können GP, Böhm R and others (2002) Daily dataset of 20th-century surface air temperature and precipitation series for the European Climate Assessment. Int J Climatol 22:1441-1453

Koscielny-Bunde E, Roman HE, Bunde A, Havlin S, Schellnhuber HJ (1998) Long-range power-law correlations in local daily temperature fluctuations. Philos Mag B 77: $1331-1340$

Lana X, Martínez MD, Burgueño A, Serra C (2009) Statistics of hot and cold events in Catalonia (NE Spain) for the recording period 1950-2004. Theor Appl Climatol 97:135-150

Lin G, Fu Z (2008) A universal model to characterize different multi-fractal behaviors of daily temperature records over China. Physica A 387:573-579

López JL, Contreras JG (2013) Performance of multifractal detrended fluctuation analysis on short time series. Phys Rev E 87:022918

Lovejoy S, Pinel J, Schertzer D (2012) The global space-time cascade structure of precipitation: satellites, gridded gauges and reanalyses. Adv Water Resour 45:37-50

Lüdecke HJ, Link R, Ewert FK (2011) How natural is the recent centennial warming? An analysis of 2249 surface temperature records. Int J Mod Phys C 22:1139-1159

Mali P (2014) Multifractal characterization of global temperature anomalies. Theor Appl Climatol, doi:10.1007/s00704014-1268-y

> Maraun D, Rust HW, Timmer J (2004) Tempting long-memory-on the interpretation of DFA results. Nonlinear Process Geophys 11:495-503

Martínez MD, Serra C, Burgueño A, Lana X (2010) Time trends of daily maximum and minimum temperatures in Catalonia (NE Spain) for the period 1975-2004. Int J Climatol 30:267-290

Min L, Shuang-Xi Y, Gang Z, Gang W (2013) Multifractal detrended fluctuation analysis of interevent time series in a modified OFC model. Commun Theor Phys 59:1-6

Oświęcimka P, Kwapień J, Drożdż S (2006) Wavelet versus detrended fluctuation analysis of multifractal structures. Phys Rev E 74:016103
Palus M (2008) Bootstrapping multifractals: surrogate data from random cascades on wavelet dyadic trees. Phys Rev Lett 101:134101

Palus M, Novotna D, Zvelebil J (2004) Fractal rock slope dynamics anticipating a collapse. Phys Rev E 70:036212

> Pavón-Domínguez P, Serrano S, Jiménez-Hornero FJ, Jiménez-Hornero JE, Gutiérrez de Ravé E, ArizaVillaverde AB (2013) Multifractal detrended fluctuation analysis of sheep livestock prices in origin. Physica A 392:4466-4476

Rodríguez R, Casas MC, Redaño A (2013) Multifractal analysis of the rainfall time distribution on the metropolitan area of Barcelona (Spain). Meteorol Atmos Phys 121: 181-187

Rötter RP (2014) Agricultural impacts: robust uncertainty. Nat Clim Change 4:251-252

Sivakumar B (2000) Fractal analysis of rainfall observed in two different climatic regions. Hydrol Sci J 45:727-738

Schertzer D, Lovejoy S (1988) Multifractal simulations and analysis of clouds by multiplicative processes. Atmos Res 21:337-361

> Stan C, Cristescu MT, Iarinca LB, Cristescu CP (2013) Investigation on series of length of coding and non-coding DNA sequences of bacteria using multifractal detrended cross-correlation analysis. J Theor Biol 321:54-62

Swanson KL, Tsonis AA (2010) Has the climate recently shifted? Theor Appl Climatol 102:75-85

Telesca L, Lovallo M (2011) Analysis of the time dynamics in wind records by means of multifractal detrended fluctuation analysis and the Fisher-Shannon information plane. J Stat Mech 2011:P07001

Theiler J, Galdrikian B, Longtin A, Eubank S, Farmer DJ (1992) Using surrogate data to detect nonlinearity in time series. In: Casdagli M, Eubank S (eds) Nonlinear modeling and forecasting. Addison-Wesley, Redwood City, CA, p 163-188

Trnka M, Rötter RP, Ruiz-Ramos M, Kersebaum KC, Olesen JE, Žalud Z, Semenov MA (2014) Adverse weather conditions for European wheat production will become more frequent with climate change. Nat Clim Change 4: 637-643

Valencia JL, Requejo AS, Gascó JM, Tarquis AM (2010) A universal multifractal description applied to precipitation patterns of the Ebro River Basin, Spain. Clim Res 44: $17-25$

Venäläinen A, Tuomenvirta H, Pirinen P, Drebs A (2005) A basic Finnish climate data set 1961-2000: description and illustration. Finnish Meteorological Institute Reports 5. Finnish Meteorological Institute, Helsinki

Veneziano D, Langousis A, Furcolo P (2006) Multifractality and rainfall extremes: a review. Water Resour Res 42: W06D15

Venugopal V, Roux SG, Foufoula-Georgiou E, Arneodo A (2006) Revisiting multifractality of high-resolution temporal rainfall using a wavelet-based formalism. Water Resour Res 42:W06D14

Yonghe L, Kexin Z, Wanchang Z, Yuehong S, Hongqin P, Jinming $F$ (2013) Multifractal analysis of 1-min summer rainfall time series from a monsoonal watershed in eastern China. Theor Appl Climatol 111:37-50

Yu ZG, Leung Y, Chen YD, Zhang Q, Anh V, Zhou Y (2014) Multifractal analyses of daily rainfall time series in Pearl River basin of China. Physica A 405:193-202

Yuan N, Fu Z, Mao J (2013) Different multi-fractal behaviors of diurnal temperature range over the north and the south of China. Theor Appl Climatol 112:673-682 